\title{
The Effect of Education Based Health Belife Model on Preventive Behaviors of Mother About Iron Deficiency Anemia in Children: Aneducational Controlled Trial
}

Mohammadzadeh larijani

Arak University of Medical Sciences

Mahboobeh Khorsandi ( $\nabla$ dr.khorsandi@arakmu.ac.ir )

Arak University of Medical Sciences

Mohsen Shamsi

Arak University of Medical Sciences

Mehdi Ranjbaran

Arak University of Medical Sciences

\section{Research Article}

Keywords: Education, Mother, Children, Iron Deficiency Anemia, Health Belief Model

Posted Date: November 22nd, 2021

DOI: https://doi.org/10.21203/rs.3.rs-750417/v1

License: (a) (i) This work is licensed under a Creative Commons Attribution 4.0 International License.

Read Full License 


\section{Abstract}

\section{Background}

Iron deficiency anemia (IDA) is the most common hematological disease in infancy and childhood. Therefore, it is necessary to provide maternal education using models that identify factors affecting behavior. Hence, this study was conducted to evaluate the effect of maternal education based on the health belief model (HBM) on preventive behaviors of IDA in children aged 1-6 years in rural health centers of Babol, Mazandaran Province, Iran in 2015.

\section{Methods}

In this randomized controlled trial, 119 mothers were selected through multi-stage random sampling and divided into two groups of intervention and control. The data collection tool was a researcher-made questionnaire whose validity and reliability were studied and confirmed. A pretest was conducted in both groups. Need assessment was done according to the pretest results, and educational intervention was performed in four educational sessions in the intervention group. The same questionnaire was applied for posttest three months after the intervention. SPSS version 20 was used for data analysis.

\section{Results}

There was no significant difference in the mean scores of awareness, HBM constructs, and performance of the mothers between the two groups before the intervention $(P>0.05)$ while the difference was significant after the intervention $(P<0.001)$. The mean score of performance, increased significantly from 80.84 to 88.68 in the intervention group after the intervention $(P<0.001)$.

\section{Conclusion}

Educational intervention, according to the HBM based on a primary needs assessment effectively improves maternal performance about IDA prevention in children. Therefore, it is suggested that these interventions replace conventional educational programs.

Trial registration: This trial has been registered at IRCT, IRCT2014082118892N1. Registered on 2014-1123, https://en.irct.ir/trial/17015

\section{Background}

Iron Deficiency Anemia (IDA) is the most prevalent nutritional problem and common cause of anemia. It is estimated that about $18-38 \%$ of children below 5 years in Iran are anemic (1). Different studies in various parts of Iran like Jahrom (2), Rafsanjan(3), Birjand(4), Babol (5)and Qom(6), as well as a study by Sayari(7) have reported unfavorable results of IDA in children below and above 5 years. Iron is an essential nutrient for blood production that should be supplied through diet. If enough iron is not available for red blood cell production, the body first uses its own reserves. Then, if iron deficiency 
continues, iron reserves decrease gradually leading to depletion of iron stores, eventually resulting in IDA $(7,8)$. According to Tatala et al, half of school-age children suffer from anemia(9). Researchers believe that IDA in school-age children indicates iron deficiency at earlier ages. Childhood anemia continues in later ages and due to the high growth speed of children, especially below 2 years of age, iron deficiency is associated with irreversible and irrecoverable sequelae in these children (6).

It is now clear that mild to moderate iron deficiency, even without anemia, had adverse effects on the cognitive function, physical growth, behavior, and immunity, and is associated with complications of infectious diseases in nursery and school age children(10).

The leading cause of anemia in developing countries is low iron intake and low bioavailability of the dietary iron. Eating habits like vegetarian diets and insufficient intake of animal products also contribute to IDA. Increased bioavailability of iron has an important effect on enhancing the quality of dietary iron(11); therefore, proper nutritional education to use a balanced and diverse diet is one of the most important measures to prevent IDA. Nutritional education for IDA prevention is based on using enhancers of iron absorption or avoiding co-administration of iron and iron absorption inhibitors. Education of preventive behaviors include intake of iron supplements, iron-rich foods(12), environmental health and control of parasitic diseases, immunization and treatment of infections (12);(11);(12);(13), avoiding use of bread made of non fenmented dough, and modification of dietary patterns can help to prevent IDA. Therefore, health education programs aiming at IDA prevention should be presented to mothers as the major caregivers of children who are responsible for their health and well-being.

Research has shown that model-based structured education is more successful than conventional education(14). One of these models, the Health Belief Model (HBM), is a psychological model that suggests the person's knowledge and attitude predict behavior. This model is used to determine the relationship between health beliefs and engagement in health-promoting behavior(15). A review of the literature showed that no similar study used this model.Researcher used this model to promote IDA and some other health-related behaviors and its promising results have indicated the success of HBM-based education in promoting health behaviors of learners((16), (17), (18).It seems that the HBM is effective in prevention of IDA in children because it can enhance the mothers' perceived susceptibility and severity regarding IDA preventive behaviors in children; therefore, the mothers perceive that their children are susceptible to IDA and learn about the severity and complications of IDA following not adopting preventive behaviors. A combination of these two, i.e. perceived susceptibility and perceived severity, produces perceived threat about IDA. Then, with regards to the perceived benefits of preventive behaviors and analysis of potential barriers, and through promoting self-efficacy (i.e. developing self-confidence in the person) and use of external and internal cues to action and stimuli affecting the person, e.g. the physician, health care personnel, other mothers, books, and media, a feeling of responsibility, fear of the complications, etc., the person is driven towards adopting IDA preventive behaviors.

The present study was conducted in mothers of 1-6 year-old children to evaluate The effect of maternal education on preventive behaviors of iron deficiency anemia in children. The results of this study can be 
used in designing theory-based preventive policies and educational programs to promote pediatric IDA preventive behaviors.

\section{Methods}

\section{Study design}

An educational intervention was applied in this randomized controlled trial. The Ethics Committee of Arak University of Medical Sciences (ethics code: 93-169-4) and Ethic Committee of Babol County approved the study protocol.

\section{Hypothesis}

To determine the effect of education based on the health belief model on promoting preventive behaviors from child iron deficiency anemia in mothers with children aged one to six years.

1. To compare the mean score of knowledge about preventive behaviors from iron deficiency anemia, after educational intervention in the intervention and control group.

2. To compare the mean score of perceived susceptibility, perceived severity, perceived benefits, perceived barriers and perceived self-efficacy regarding iron deficiency anemia, before and after intervention in the intervention and control group.

3. To compare the average performance score for behaviors that prevent iron deficiency anemia, after educational intervention in the Intervention and control group

4. To compare the mean score of cues to action on preventive behaviors from iron deficiency anemia, after educational intervention in the intervention and control group

\section{Sample size estimation}

The sample size was calculated 132 mothers (66 in the intervention group and 66 in the control group) with regards to a similar previous study (17), standard deviation of 25.33 , mean difference of 15 , confidence interval of $95 \%$, statistical power of $90 \%$, and attrition of $10 \%$. Finally, the data of 59 intervention and 60 controls were analyzed. Multi-stage random sampling was applied to select the participants. All rural health centers of Babol were considered as strata. In each region, one rural health center, and in each rural health center, two rural health houses were randomly selected. One health house was used as the intervention center and the other was used as the control center. In total, four health houses were used as intervention centers and four were used as control centers. Seventeen children were randomly selected in each health house using the infant care register and their mothers were contacted. The objectives of the study were explained to mothers and their informed consent was obtained if they agreed to participate in the study. The inclusion criteria were having a 1-6 year-old child, being selected in random sampling, and no history of anemia or other related diseases like Gastero Intestinal diseases in the child according to medical records and mother's statement and mothers with literate at least for reading and writing skills. 
The exclusion criteria were lack of interest in participation in the study, loss of motivation during the study, and missing more than one educational session. First, the participants were randomly assigned to the intervention and control groups (each group included 66 participants). Then, the level of knowledged , perceived susceptibility, perceived severity, perceived benefits, perceived barriers, cues to action, behavior, and self-efficacy regarding IDA preventive behaviors was assessed in both groups using a pretest questionnaire.

\section{Measures}

The data collection tool before and after the intervention was a researcher-made questionnaire containing demographic data and an IDA questionnaire according to the HBM. This questionnaire contained 16 questions on knowledge. Moreover, perceived susceptibility (7 questions), perceived severity (4 questions), perceived benefits (7 questions), perceived barriers (9 questions), perceived self-efficacy (6 questions), external and internal cues to action (10 questions), and performance of the mothers regarding IDA preventive behaviors in their 1-6 year-old children were assessed using a checklist (20 questions) with a 5-point Likert scale. As for scoring, in the awareness section, a correct answer scored one and a wrong answer scored zero, and the total score of this section was calculated out of 100 through dividing the number of correct answer by the total number of questions multiplied by 100 . For perceived susceptibility, severity, benefits, and barriers, the score of each question ranged from 1 to 5 (I completely disagree $=1$, I disagree $=2$, I have no idea $=3$, I agree=4, I completely agree=5). The score of these sections was also calculated out of 100. In the performance section, a correct behavior scored one and a wrong behavior scored zero. The score of this section was also calculated out of 100 .

The content validity of the instrument was evaluated and confirmed by experts. To assess the reliability of the questionnaire, it was administered to 30 mothers of children aged 1-6 years who were demographically similar to the study population. The Cronbach's alpha of awareness, perceived susceptibility, perceived severity, perceived benefits, perceived barriers, perceived self-efficacy, cues to action, and performance was $0.62,0.69,0.80,0.9,0.83,0.72,0.73$, and 0.74 , respectively. The Cronbach's alpha of the instrument was 0.85 .

\section{Educational Intervention}

The educational intervention was performed in the intervention group (based on the pretest results as an educational needs assessment) after determining knowledge and other components of the HBM and preparing the educational content accordingly. The educational intervention was presented in four educational sessions, each lasting 40 minutes, using lecture, group discussion, and Role playing. Moreover, the pamphlets, booklets, and video CDs were used for a more effective content delivery. Finally, three months after the educational intervention, the same questionnaire was used in both groups for pretest.

in the first session that was designed to promote knowledge of mothers ,they became familiar with IDA and its signs and symptoms as well as the causes and preventive factors. In the second session, the 
participants were provided with HBM-based education to enhance their perceived susceptibility and severity regarding IDA in order to improve the mothers' attitude towards the complications, causes, and preventive factors of this disease in their children. In the third session, the researcher discussed the benefits and barriers of IDA preventive behaviors in children and tried to underline the perceived benefits (to downplay the barriers). The fourth session was spent on perceived self-efficacy, cues to action, empowering of mothers regarding IDA preventive behaviors in their children, familiarizing mothers with different information sources about IDA preventive behaviors, and enhancing their performance using internal and external cues to action. Since acquiring information from "health centers staff" received the highest score in cues to action on the pretest, education was provided by the researcher as a health care provider in the health house, or upon agreement of mothers, in a nearby large mosque. In these sessions, PowerPoint slides, pamphlets, booklets, and videos were employed to achieve educational objectives (cognitive, emotional, and psychological).(figure 1)

\section{Statistical analysis}

Data analyses were performed using IBM SPSS Statistics for Windows, Version 20 through descriptive and inferential statistics (including independent t-test, paired t-test, Chi-square). The significance level was considered at 0.05 . To investigate the normality of the data, Histogram, Q-Q plot and KolmogorovSmirnov test was used and normal distribution of the data was obtained.

\section{Ethical considerations}

The Ethics Committee of Arak University of Medical Sciences (ethics code: 93-169-4) and Ethic Committee of Babol County approved the study protocol. This trial has been registered at IRCT, IRCT2014082118892N1. Written informed consent was obtained from all the participants.educational material was shared with the control group at the end of the study.

\section{Results}

\section{Sample characteristics}

The mean age of the mothers was $31.0 \pm 5.8$ and $29.8 \pm 5.0$ years in the intervention and control group (Table1), respectively. Other demographic characteristics are presented ( Table 1 and 2). The results of independent t-test and chi-square showed no significant difference in qualitative and quantitative variables between the intervention and control group ( Table 1 and 2).

\section{Evaluation of intervention}

The independent t-test was also applied to compare the mean score of HBM constructs between the two groups before the intervention. The results showed no significant difference in the variables of knowledge, perceived susceptibility, perceived severity, perceived benefits, perceived barriers, self-efficacy, cues to action, and performance between the two groups before the intervention. 
The results of independent t-test showed no significant difference in the mean scores of awareness and performance regarding pediatric IDA preventive behaviors between the two groups before the intervention $(P>0.05)$, while the difference between the two groups was significant 12 weeks after the intervention $(P<0.001)$. Paired t-test showed a significant difference in the mean score of awareness and performance before and after the education in the intervention $(P<0.001)$ and control group $(P<0.05)$.

Independent t-test showed no significant difference in the mean scores of HBM constructs regarding pediatric IDA preventive behaviors between the two groups before the intervention $(P>0.05)$, while the difference between the two groups was significant in all constructs $(P<0.001)$ except for cues to action $(P=0.17)$ three months after the intervention. The results of paired t-test showed a significant improvement in the mean scores of all HBM constructs in the intervention group after the education $(P<0.001)$, while no significant difference was observed in the HBM constructs except for cues to action before and after the intervention in the control group $(P>0.05)$ ( Table 3$)$.

\section{Discussion}

The score of knowledge was low in intervention and control groups before educational intervention; however, this even low level of knowledge is most probably acquired from health care providers, TV, physicians, newspapers and books, other mothers, and radio. The significant increase in the mean score of knowledge after the intervention can be due to receiving education about IDA preventive behaviors. These sessions improved knowledge about IDA prevention by 47 scores $(91.3 \%)$ in the intervention group. This finding was similar to the results of studies by Hassan et al. (18) in mothers of children suffering from IDA in the UAE, Mansourian et al. (16) about IDA prevention in children, Ghafari et al. (19) on enhancing nutritional behaviors of osteoporosis prevention in female students, Shamsi \& Sjadi, (20) on preventive behaviors of febrile convulsion in children. However, Tavasoli et al. (21) evaluated the knowledge and attitude of female teachers regarding osteoporosis prevention and reported different results. It should be noted that teachers are a special group of the society with a rather similar socioeconomic status, while our study population included subjects from different classes of the society, and this difference should be considered in designing and delivering the educational material.

In this study, the mean score of knowledge also increased significantly in the control group, which is in line with the results of a study by Shojaeizadeh et al(22). This finding can be attributed to the effect of pretest questionnaire which encouraged mothers to use different information sources to find answers to the questions during these 12 weeks, resulting in an increase in their score of knowledge (21 scores).

However, it should be noted that increased knowledge alone might not result in performance change. Therefore, to make a change in the performance, in addition to knowledge, interventions on the attitude are also required. In this regard, Kang conducted a study on the Korean students' knowledge and attitude about breast milk(23). Although education is associated with knowledge enhancement, an attitude change is necessary to improve reaction $(24,25)$. 
In a study by Sharifirad et al, despite adequate awareness, the patients did not adhere to diet recommendations(26). The significant increase in the mean score of susceptibility after the education in the intervention group indicates the effectiveness of education in enhancing perceived susceptibility since after the intervention, most of the mothers in the intervention group believed that their children might be at risk of IDA. An increase in the mean score of perceived susceptibility was also reported in other studies(16), (20), (27), (28), (29), (19),(30). Our study also showed a significant difference in the perceived severity between the two groups after the intervention, which is in line with the results of studies by Ebadi \& Solhi (27)Tol et t al.(28), Mansourian et al.(16), Hassan et al.(18), Razi et al.(29), Ghafari et al.(19), and Gilasi et al(30).

In our study, it seems that reminding mothers of the severe complications of IDA, especially delayed growth and development as well as economic burdens and cognitive disturbances, was an important factor in improving their perceived severity. Before the intervention, the subjects in both groups had a good understanding of the benefits of IDA prevention that improved far more in the intervention group after the intervention (13.4 scores), causing a significant difference between the two groups. This finding was in line with studies conducted by Razi et al. (29)Gilasi et al.(30), Ghafari et al.(19), Ebadi \& Solhi(27), although Mansourian et al. reported different results(16).

Mothers believed that their attempts to prevent diseases (like IDA, thyroid disorders through screening, etc.) in their children had more benefits compared to the children's attempts in this regard. There was no significant difference in the perceived barriers of IDA prevention between the two groups, while a significant difference in this construct between the two groups after the intervention indicates the effectiveness of the educational intervention in removing perceived barriers (a decrease of 14 scores in the perceived barriers) in the intervention group. Tol et al.(28), Ebadi \& Solhi (27)Shamsi \& Sajadi(20)Razi et al. (29)Ghafari(19) and Hassan et al. (18) reported similar and Mansourian et al.(16) and Gilasi et al. (30) reported different results in this regard. In the study by Gilasi et al. (30) removal of the barriers required preparation of infrastructures and provision of some facilities.

Sharifirad et al. (31) also reported that a decrease in perceived barriers was associated with a decrease in smoking in adolescents. In a study by Reisi et al.(32), mothers did not use iron supplements since they believed it had some side effects, like bad odor and taste, GI and dental side effects, and stool discoloration, resulting in lack or irregular use of iron by children. The findings of the study showed no significant difference in perceived self-efficacy between the two groups before the educational intervention; while a significant difference in this construct between the two groups after the intervention showed the effect of intervention on improved perceived self-efficacy ( 15 scores). This finding was consistent with the results of studies conducted by Hazavehi et al. (33)Ebadi \& Solhi, (27)Tol et al.(28), and Razi et al.(29). Self-efficacy connecting factors between awareness and behavior, and is the belief in self to exhibit a behavior since mere knowledge of the reason of a behavior does not result in displaying it and the person should see himself capable of doing it. Perceived self-efficacy is an introduction to a behavior, and therefore requires a special attention(34). There was no significant difference in cues to action regarding IDA preventive behaviors between the two groups before the intervention. After the 
intervention, the mean score of cues to action increased in both groups, but the increase was more prominent in the intervention group. It seems that exposure to the pretest questionnaire created some questions in the mothers that motivated them to find their answers, resulting in an increase in the score of cues to action in the control group. This finding was in line with the results of studies conducted by Mansourian et al.(16), Gilasi et al (30),Razi et al.(29), and Tol et al.(28). Shamsi et al. (20) also reported that the most important internal factor motivating mothers to display oral health behaviors was a feeling of responsibility towards the health of the fetus and infant.

There was no significant difference in the mean score of performance between the two groups while the difference between the two groups was significant after the intervention, which could be attributed to the positive effect of education. Razi et al(16), Hassan et al.(18), Mansourian et al. (16) and Ghafari et al. (19)reported similar results. In all the above studies, HBM-based education improved performance in various fields.

Limitation :The limitation of this study is reporting of anemia behavior prevention based on self-report. Moreover one of the limitations of the present study, which also exists in most human studies, was lack of control on the samples and follow-up of their adherence to preventive behaviors at home. The data were collected based on self-reports, which could affect the data quality. The objectives and benefits of the research were discussed with mothers at the time of pretest to persuade them to join the study. Several educational sessions with a smaller number of mothers were held to overcome the issue of nonattendance.

\section{Conclusion}

The results of the present study showed that designing and implementing an educational program based on the health belief model can cause a significant change in the level of awareness, attitude, and performance of the others regarding IDA preventive behaviors, indicating the necessity of well-designed educational interventions for adoption of preventive behaviors. Therefore, it is recommended that this model of educational intervention be applied in the educational programs of other rural health centers instead of conventional educational methods. Moreover, this educational model can be also used in mass media like the TV and radio to promote preventive behaviors.

\section{Declarations}

\section{Ethics approval and consent to participate}

The present study was approved by Research Council of Arak University of Medical Sciences (Grant Number:4202). The ethics committee approval code number is (93-169-4). This study has been registered in Clinical Trial Registry with the code of IRCT2014082118892N1. Informed written consent was obtained from the mothers and all the procedures performed in the study involving human participants, were in accordance with the ethical standards. 


\section{Consent for publication}

Not applicable.

\section{Availability of the data and materials}

The datasets generated during and analyzed during the current study are available from the corresponding author.

Competing Interest:: The authors declare that they have no conflicts of interest.

\section{Funding}

This study was based on the result of a master's degree thesis approved by Arak University of Medical Sciences in 2014 (project number: 4202), which was financially supported by the University, as well.

\section{Authors' contributions}

$\mathrm{M} \mathrm{N}$ and $\mathrm{KH} \mathrm{M}$ and SH M and RM designed the study, MN, implemented intervention, $\mathrm{MN}$ and $\mathrm{KH} \mathrm{M}$ and $\mathrm{RM}$ analyzed data, M N and KH M and SH M RM prepared manuscript .All authors review manuscript.

\section{Acknowledgment}

This study was based on the result of a master's degree thesis approved by Arak University of Medical Sciences in 2014 (project number: 4202), which was financially supported by the University, as well. The authors wish to thank the Research Deputies of Babol and Arak medical universities, heath care staff and authorities of the health centers of Galugah, Darvish Khak, Seeyed Kola, and East Mian Mahaleh, as well as Dr Masoomeh Bayani ,Dr Jalil Seyedi ,Dr Heidar Akbarzadeh Pasha and the mothers who participated in this study.

\section{References}

1. Ghasemi A, Keikhaei B. Effects of Nutritional variables in children with iron deficiency anemia. International Journal of Pediatrics. 2014;2(3.1):183-7.

2. Nehlea PA, Saeed S. A study on the occurrence of iron deficiency anemia in 1-6 year old children referring to health care centers in Jahrom, 1385. Journal of jahrom university of medical sciences. 2010;8(2):41-6.

3. DERAKHSHAN S, DERAKHSHAN R. The prevalence of Iron deficiency anemia in 4-6 years old children of kindergardens at Rafsanjan City in 2006. 2007.

4. Fesharakinia A. The prevalence of iron deficiency and its anemia in 1-5 years old children and their mothers in Birjand City. Journal of Fasa University of Medical Sciences. 2014;3(4):325-9.

5. Mehrabian F, Mahdavi Roshan M, Atrkar Roshan Z, Kasmaei P, Valipour R. Survey status and nutritional behavior to prevention of iron deficiency anemia among high school girls in Babol City. 
The Journal of Urmia Nursing and Midwifery Faculty. 2014;11(12):1015-23.

6. Abedini Z, Lotfı MM, Parvizi F. Prevalence of iron deficiency anemia and its related factors in school age children. Pajoohandeh Journal. 2010;15(5):208-12.

7. Sayyari A, Sheikhol Eslam R, Abdollahi Z. Prevalence of anaemia in 2-12-year-old Iranian children. 2006.

8. Kadivar MR, Yarmohammadi H, Mirahmadizadeh AR, Vakili M, Karimi M. Prevalence of iron deficiency anemia in 6 months to 5 years old children in Fars, Southern Iran. Medical Science Monitor. 2003;9(2):CR100-CR4.

9. Tatala S, Kihamia C, Kyungu L, Svanbergrhaaa U. Risk factors for anaemia in schoolchildren in Tanga Region, Tanzania. Tanzania journal of health research. 2008;10(4).

10. Who U. UNU. Iron deficiency anaemia: assessment, prevention and control, a guide for programme managers Geneva: World Health Organization. 2001:1-114.

11. Rashidi M, Ebrahimzadeh F, Karbasi S, Shokrollahi N. Effect of nutritional education on irondeficiency anemia in high schools girls. Journal of Shahrekord Uuniversity of Medical Sciences. 2010;12.

12. Vucic V, Berti C, Vollhardt C, Fekete K, Cetin I, Koletzko B, et al. Effect of iron intervention on growth during gestation, infancy, childhood, and adolescence: a systematic review with meta-analysis. Nutrition reviews. 2013;71(6):386-401.

13. Subramaniam G, Girish M. Iron Deficiency Anemia in Children: Authors' Reply. The Indian Journal of Pediatrics. 2016;83(2):193-.

14. Legler J, Meissner HI, Coyne C, Breen N, Chollette V, Rimer BK. The effectiveness of interventions to promote mammography among women with historically lower rates of screening. Cancer Epidemiology and Prevention Biomarkers. 2002;11(1):59-71.

15. Glanz K, Rimer BK, Viswanath K. Health behavior and health education: theory, research, and practice: John Wiley \& Sons; 2008.

16. Mansourian M, Qorbani M, Rahimzadeh Bazraki H, Charkazi A, Asayesh H, Rezapoor A. Effect of nutritional education based on HBM model on anemia in Golestan girl guidance school students. Iranian Journal of Health Education and Health Promotion. 2013;1(2):51-6.

17. Reisi M, Alidosti M, Tavassoli E, Kargar M, Dehkordi ZR, Hafez AA. Investigating of Mothers' Behavior Based on the Health Belief Model about Using Iron Supplementation in 6 to 24-Month Old Children in Shahrekord City, Iran. Journal of Advances in Medicine and Medical Research. 2015:1140-6.

18. Hassan AE, Kamal MM, Fetohy EM, Turky GM. Health education program for mothers of children suffering from iron deficiency anemia in United Arab Emirates. The Journal of the Egyptian Public Health Association. 2005;80(5-6):525-45.

19. GHAFFARI M, TAVASSOLI E, ESMAILLZADEH A, HASANZADEH A. The effect of education based on health belief model on the improvement of osteoporosis preventive nutritional behaviors of second grade middle school girls in Isfahan. 2011. 
20. Shamsi M, Hidarnia A, Niknami S, Rafiee M, Zareban I, Karimy M. The effect of educational program on increasing oral health behavior among pregnant women: Applying health belief model. Health Education \& Health Promotion. 2013;1(2):21-36.

21. TAVASOLI e, raeisi $m$, mazaheri $m$, alidosti $m$, zamanianazodi $m$, abbaszadeh $m$. Knowledge and Perceptions of Prevention of Osteoporosis Among Shahr-e-kord Female Teachers. scientific journal of ilam university of medical sciences. 2013;21(4):136-42.

22. SHOJAEZADEH D, SADEGHI R, TARRAHI MJ, ASADI M, LASHGARARA B. APPLICATION OF HEALTH BELIEF MODEL IN PREVENTION OF OSTEOPOROSIS IN VOLUNTEERS OF KHORRAMABAD CITY HEALTH CENTERS, IRAN. 2012.

23. Kang N-M, Song Y, Im E-O. Korean university students' knowledge and attitudes toward breastfeeding: a questionnaire survey. International journal of nursing studies. 2005;42(8):863-70.

24. Karami Matin B, Sepahi S, Khoshay A, Sepahi V, Shahabadi S, Laghaei Z. The effect of training based on health belief model on the awareness and attitude of nursing and midwifery students in preventing cardiovascular diseases. Edu Res Med Sci. 2013;1(2):28-33.

25. Ahmadi Z, Shamsi M, Roozbahani N, Moradzadeh R. The effect of educational intervention program on promoting preventive behaviors of urinary tract infection in girls: a randomized controlled trial. BMC pediatrics. 2020;20(1):1-10.

26. Sharifirad GR, Tol A, Mohebi S, Matlabi M, Shahnazi H, Shahsiah M. The effectiveness of nutrition education program based on health belief model compared with traditional training. Journal of education and health promotion. 2013;2.

27. Ebadi fard Azar F, Solhi M. The impact of health education through Health Belief Model (HBM) on mother's perceptions about obesity children obese male student in elementary schools (17th district, Tehran City). Journal of Health Administration. 2006;8(22):7-14.

28. Tol A, Majlessi F, Shojaeizadeh D, ESMAELEE SS, Mahmoudi MM, Moradian M. Effect of the educational intervention based on the health belief model on the continuation of breastfeeding behavior. 2013.

29. Razi T, Shamsi M, Khorsandi M, Roozbahani N, Ranjbaran M. Assessing health belief model construct in paying attention to danger signs in children less than five years old. Journal of Mazandaran University of Medical Sciences. 2015;25(124):218-23.

30. Gilasi HR, Babaee MA, Heidarian M, Tavassoli E. The effect of health education based on Health Belief model on mother's participation for neonatal hypothyroidism screening program. Iranian Journal of Endocrinology and Metabolism. 2013;15(3):285-91.

31. Sharifi-rad G, Hazavei MM, Hasan-zadeh A, Danesh-amouz A. The effect of health education based on health belief model on preventive actions of smoking in grade one, middle school students. Journal of Arak university of medical sciences. 2007;10(1):79-86.

32. Reisi M, Alidosti M, Tavassoli E, Kargar M, Dehkordi Z, Hafez A. Investigating of mothers' behavior based on the health belief model about using iron supplementation in 6 to 24-month old children in Shahrekord city, Iran. British Journal of Medicine and Medical Research. 2015;5(9):1140-6. 
33. Hazavehi MM, Taheri M, Moeini B, Roshanaei G. The effect of educational program on mother's child (6 to 9 month age) for reducing growth failure in Hamadan: applying Health Belief Model (HBM). Jundishapur Journal of Health Sciences. 2013;5(2):129-39.

34. Hendricks CS, Hendricks DL, Webb SJ, Davis JB, Spencer-Morgan B. Fostering self efficacy as an ethical mandate in health promotion practice and research. Online Journal of Health Ethics. 2005;2(1):6.

\section{Tables}

Table 1: Comparison of quantitative demographic variables of the mothers and children between intervention and control groups

\begin{tabular}{llll} 
& Control Group & Intervtion Group & P-value \\
\hline Variable & Mean \pm SD & Mean \pm SD & \\
\hline Age, mothers (year) & $31.07 \pm 5.80$ & $29.85 \pm 5.06$ & 0.22 \\
\hline Age, Children (Year) & $3.84 \pm 1.58$ & $3.91 \pm 1.76$ & 0.80 \\
\hline Spouse's education & $9.56 \pm 3.52$ & $9.37 \pm 3.60$ & 0.80 \\
\hline Number of children & $1.64 \pm 0.71$ & $1.85 \pm 0.75$ & 0.12
\end{tabular}

Table 2: Comparison of qualitative demographic variables of the mothers and children between intervention and control groups

\begin{tabular}{|c|c|c|c|c|}
\hline \multirow[t]{2}{*}{ Variable } & \multirow[t]{2}{*}{ Group } & Intervention & Control & \multirow[t]{2}{*}{ P-value } \\
\hline & & Number (\%) & Number (\%) & \\
\hline \multirow[t]{2}{*}{ Mother's occupational status } & working & $1(1.7)$ & $3(5.0)$ & \multirow[t]{2}{*}{0.317} \\
\hline & Housewife & $58(93.3)$ & $57(95.0)$ & \\
\hline \multirow[t]{2}{*}{ Housing status } & owned & $53(89.8)$ & $54(90.0)$ & \multirow[t]{2}{*}{0.976} \\
\hline & rented & $6(10.2)$ & $6(10.0)$ & \\
\hline \multirow[t]{2}{*}{ First child } & Yes & $29(49.2)$ & $22(36.7)$ & \multirow[t]{2}{*}{0.169} \\
\hline & No & $30(50.8)$ & 38 (63.3) & \\
\hline \multirow[t]{3}{*}{ Maternal education } & Primary school & $6(10.2)$ & $11(18.3)$ & \multirow[t]{3}{*}{0.091} \\
\hline & Middle School & $11(18.6)$ & $20(33.3)$ & \\
\hline & High school & 35 (59.3) & $24(40)$ & \\
\hline
\end{tabular}


Table 3: Comparison of mean score of performance regarding IDA preventive behaviors and HBM constructs before and after the education in intervention and control groups and the mean change score in two groups 


\begin{tabular}{|c|c|c|c|c|c|}
\hline & & Before & After & & Change score \\
\hline Variable & Group & Mean $\pm S D$ & Mean $\pm S D$ & P-value* & Mean $\pm S D$ \\
\hline \multirow[t]{3}{*}{ Awareness } & Intervention & $43.32 \pm 16.77$ & $91.31 \pm 8.37$ & 0.001 & $47.98 \pm 17.99$ \\
\hline & Control & $42.08 \pm 15.89$ & $63.54 \pm 16.11$ & 0.001 & $21.45 \pm 21.50$ \\
\hline & P-value** & 0.679 & 0.001 & & 0.001 \\
\hline \multirow[t]{3}{*}{ Perceived Susceptibility } & Intervention & $74.09 \pm 7.94$ & $88.91 \pm 8.08$ & 0.001 & $14.81 \pm 9.33$ \\
\hline & Control & $75.90 \pm 10.73$ & $76.09 \pm 13.40$ & 0.91 & $0.19 \pm 13.44$ \\
\hline & P-value** & 0.298 & 0.001 & & 0.001 \\
\hline \multirow[t]{3}{*}{ Perceived severity } & Intervention & $74.74 \pm 10.92$ & $92.62 \pm 8.11$ & 0.001 & $17.88 \pm 12.60$ \\
\hline & Control & $78.25 \pm 11.89$ & $76.50 \pm 11.39$ & 0.37 & $-1.75 \pm 15.03$ \\
\hline & P-value** & 0.97 & 0.001 & & 0.001 \\
\hline \multirow[t]{3}{*}{ Perceived benefits } & Intervention & $80.04 \pm 8.10$ & $93.51 \pm 6.60$ & 0.001 & $13.46 \pm 8.57$ \\
\hline & Control & $83.38 \pm 10.42$ & $82.14 \pm 11.68$ & 0.53 & $1.23 \pm 15.22$ \\
\hline & P-value** & 0.05 & 0.001 & & 0.001 \\
\hline \multirow[t]{3}{*}{ Perceived barriers } & Intervention & $47.19 \pm 9.95$ & $32.20 \pm 10.12$ & 0.001 & $-14.99 \pm 11.00$ \\
\hline & Control & $46.03 \pm 16.52$ & $42.44 \pm 16.80$ & 0.081 & $-3.59 \pm 15.64$ \\
\hline & P-value** & 0.64 & 0.001 & & 0.001 \\
\hline \multirow[t]{3}{*}{ Self-efficacy } & Intervention & $72.65 \pm 11.12$ & $87.85 \pm 9.34$ & 0.001 & $15.19 \pm 11.53$ \\
\hline & Control & $76.11 \pm 12.32$ & $75.44 \pm 15.51$ & 0.68 & $-0.66 \pm 12.64$ \\
\hline & P-value** & 0.11 & 0.001 & & 0.001 \\
\hline \multirow[t]{3}{*}{ Cues to action } & Intervention & $62.75 \pm 11.70$ & $76.10 \pm 10.25$ & 0.001 & $13.34 \pm 13.10$ \\
\hline & Control & $66.45 \pm 12.9$ & $73.41 \pm 11.06$ & 0.001 & $6.95 \pm 12.10$ \\
\hline & P-value** & 0.10 & 0.17 & & 0.007 \\
\hline \multirow[t]{3}{*}{ Performance } & Intervention & $80.74 \pm 6.12$ & $88.68 \pm 5.66$ & 0.001 & $7.94 \pm 6.42$ \\
\hline & Control & $79.72 \pm 7.45$ & $80.47 \pm 8.64$ & 0.437 & $0.74 \pm 7.35$ \\
\hline & P-value** & 0.41 & 0.001 & & 0.001 \\
\hline
\end{tabular}

* Paired t test, ** Independent $t$ test

Figures 


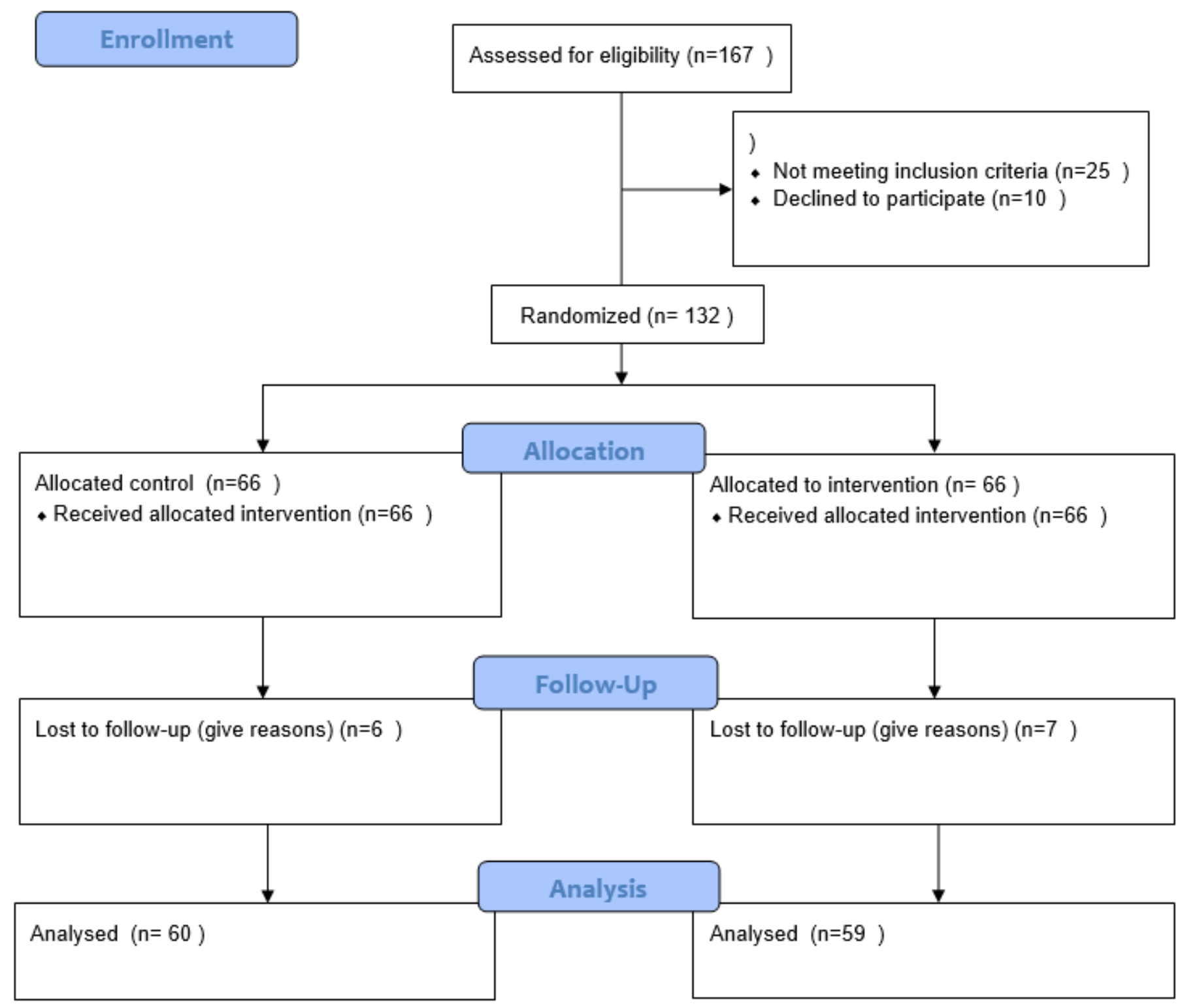

Figure 1

Intervention diagram 